\title{
Experiential learning in public health: evaluation of a health promotion campaign assessment for pharmacy students
}

\author{
Simon White (iD, Alison Gifford, Martin Frisher \\ School of Pharmacy and Bioengineering, Keele University, United Kingdom
}

\section{Keywords}

Experiential learning

Health promotion

Pharmacy education

Pharmacy students

Public health

\section{Correspondence}

Simon White

School of Pharmacy and Bioengineering

Keele University

Staffordshire

ST5 5BG

United Kingdom

s.j.white@keele.ac.uk

\begin{abstract}
Description: Students in small groups designed, delivered and evaluated real-life health promotion campaigns in the local community. A peer assessed component was included from the fifth cohort onwards. Evaluation: Six successive cohorts of pharmacy students anonymously completed an evaluation questionnaire after finishing the assessment. Descriptive and inferential statistical analyses were undertaken on the data. The results showed that consistently more respondents reported the assessment as a positive experience than a negative experience. Significantly more respondents reported peer assessment as being useful and group members equally contributing to campaign planning in the cohorts with peer assessment compared to the pre-peer assessment cohorts, but peer assessment did not significantly affect enjoyment ratings. Respondents' reported enjoyment of the assessment was significantly associated with agreement that it prepared them for health promotion in practice. Conclusions: Pharmacy students perceived the health promotion campaign assessment as appropriately challenging and enjoyable preparation for health promotion in practice.
\end{abstract}

\section{Introduction}

In recent years pharmacists in all patient-facing sectors have become increasingly involved in health promotion. Community pharmacists, for example, have become increasingly involved in developing new initiatives to promote healthy living, building on their established role in providing lifestyle-related advice and interventions (Eades et al., 2011; Brown et al., 2012; Brown et al., 2016; UK Department of Health, 2019). In the United Kingdom (UK), for example, pharmacies routinely participate in local health promotion campaigns, and some now send staff to community venues, rather than restricting campaign activity to pharmacy premises. Pharmacy public health roles have been supported by national health policy in the UK, the United States (US) and other countries, such that pharmacies are becoming seen as vital centres of wellness in local communities (UK
Department of Health, 2019). This needs to be reflected in the initial education and training of pharmacists so that they are adequately prepared to undertake these and future public health roles.

Schools of pharmacy have adopted various practical learning, teaching and assessment methods in public health, but requiring students to plan, deliver and evaluate a real-life health promotion campaign in the local community as a core part of their initial education does not appear to have been previously reported in the literature. There are reports of other practical public health curricular activities in pharmacy courses, such as students being involved in health promotion activities in placements, clerkships and other practice experiences (Anderson \& Good, 2006; Sookaneknum et al., 2009; Murphy et al., 2010; Packard et al., 2010; Linh Banh et al., 2015; Ostroff et al., 2017; Gelayee \& Mekonnen, 
2018). There are also reports of pharmacy students undertaking service learning, and research or evaluation projects on public health topics (Carter \& Cochran, 2002). Few of these initiatives appear to have been evaluated in terms of impact on students' learning, but those that were evaluated showed improvement in students' perceived self-confidence (Packard et al., 2010), and some also reported improvements in knowledge or assessment scores (Packard et al., 2010; Sookaneknum et al., 2009). There are also reports of students on other public health-related courses undertaking health promotion campaigns (McCarthy \& Pritchard, 2002; Arbuthnot et al., 2007). McCarthy and Pritchard, for example, reported on UK undergraduate environmental health officer students planning, running and evaluating campus-based health promotion campaigns for students (McCarthy \& Pritchard, 2002). Arbuthnot and colleagues described Canadian nursing students taking part in a community-based bowel cancer education and screening programme (Arbuthnot et al., 2007). These initiatives were similarly reported to have had positive effects on students' perceived learning.

In this paper, the approach adopted to learning, teaching and assessment in the health promotion campaign assessment is discussed, and the findings of a six-year multiple cohort evaluation of whether it met the curricular goal are presented. This was to provide students with an appropriately challenging but enjoyable learning experience in health promotion that prepared them for real practice in public health pharmacy. The specific aim of the evaluation of the assessment as a learning and teaching initiative was to determine whether students perceived that it had prepared them for real practice, focusing on whether it was perceived to have been appropriately challenging at Master's level, adequately supported by staff and enjoyable. The multiple cohort (serial cross-sectional) element of the evaluation aimed to determine whether there were significant differences in students' reported perceptions between cohorts and whether there were factors that were predictive of students' reported overall enjoyment of the assessment.

\section{Description of the assessment}

The health promotion campaign group assignment is an innovative approach to experiential learning, teaching and assessment in health promotion for undergraduate Master of Pharmacy (MPharm.) students. The approach draws on the body of pedagogical theory in experiential learning, particularly in recognising the importance of authenticity in the learning environment when preparing students for practice (Lave, 1993; Kolb, 1994; Tennant \&
Pogson, 1994; Race, 2005; Herrington \& Herrington, 2006). The assessment is a Master's degree level activity, designed according to the UK Quality Assurance Agency for Higher Education criteria (UK Quality Assurance Agency for Higher Education, 2014; UK Quality Assurance Agency for Higher Education, 2015). It maps to the General Pharmaceutical Council's Future Pharmacists standards for the initial education and training of pharmacists (UK General Pharmaceutical Council, 2021) and allows students to demonstrate the Miller's triangle outcome level of 'shows how' for standards directly concerned with public health (Miller, 1990). Although designed to meet UK standards, it also readily maps to other accreditation body requirements, such as the US Accreditation Council for Pharmacy Education 2016 standards concerned with public health (US Accreditation Council for Pharmacy Education, 2016). Similarly, although designed for pharmacy students, the learning activity is not pharmacy-specific and so is likely to translate well into the public health content of education and training programmes for other healthcare professionals.

Students undertake the mandatory health promotion campaign assessment in the fourth (final) year of the MPharm. programme, as a spiral curricular culmination of their learning about the underlying principles of public health, approaches to changing health behaviour, and the practice of pharmaceutical public health (Harden \& Stamper, 1999). Teaching in public health in the MPharm. programme takes a blended learning approach, which starts in the first year with the underlying principles of public health, the social determinants of health and the concept of health promotion, e.g. as defined by the World Health Organisation (World Health Organisation, 1998). As the programme progresses, students then cover theories of health behaviour change, approaches to health promotion, and the practice of pharmaceutical public health. Students are introduced to a wide range of health behaviour change theories, including the Health Belief Model (Becker, 1974), the Theory of Planned Behaviour (Ajzen, 1991), the Transtheoretical Model (Prochaska \& DiClemente, 1994) and the Behaviour Change Wheel (Michie et al., 2011). Approaches to health promotion cover concepts such as Making Every Contact Count (UK Health Education England, 2021), brief interventions and goal setting, and applying this in practice is part of students' learning about and development of communication skills. Students are expected to augment these topics with extensive self-directed study relevant to public health and health promotion. The Intended Learning Outcomes for the final year assessment include that students will be able to demonstrate a systematic understanding of the concepts of public health, health 
inequalities and health promotion, and that they will be able to develop an original health promotion campaign by drawing on a systematic and integrated knowledge of applied therapeutics in the context of public health.

Students organise themselves into groups of six to eight. They are expected to analyse local public health needs for three potential health promotion campaign ideas. They then choose a single idea to develop and deliver on the basis of their analyses. This is intended to ensure that their choice of campaign is original and clearly targeted at a specific local public health issue that can be effectively addressed by a health promotion campaign. Creative and innovative ideas for the campaign and supporting materials are encouraged and rewarded within the marking criteria. Where there are local or national health promotion campaigns already running on the same topic, students are required to justify how their campaign would complement or align with these campaigns. Groups are supported throughout the assessment through regular meetings with academic members of staff.

Preparing to deliver a health promotion campaign on their chosen topic to a public audience in the local community involves careful and meticulous planning, and groups need to consider practicality and location, as well as their campaign design and the materials they intend to use. This includes establishing a defensible (i.e. evidence-based or evidence-informed) rationale for their campaign design and materials, ensuring they have appropriate authorisation to conduct the campaign at their intended time and place with the materials they intend to use, and that they do so within a small, fixed budget of $£ 100$. All campaign materials are validated as being accurate and appropriate by academic staff prior to use in campaigns. Students are required to participate equally and actively when delivering their campaigns and ensure that their message is clear and presented in a professional manner.

Students are also expected to evaluate their campaign alongside delivering it. They then analyse the data and complete the evaluation afterwards. Each group is required to submit a concise (1500 word) final report to discuss the rationale for their topic (including the evidence of local public health need), the rationale and evidence base for their campaign method and design of promotional materials, and their evaluation strategy for their campaign. This includes the rationale for the evaluation method chosen, as well as discussing the results.

The overall group mark is determined by equally weighted assessments of fieldwork and the final report. A $10 \%$ peer assessment component was added in the fifth cohort in response to student feedback and anonymous peer assessment software becoming available on the University's Virtual Learning Environment. The fieldwork assessment covers the demonstration of skills in preparing and delivering the campaign. This includes an assessment of the campaign in situ by an academic member of staff and feedback from members of the public whom the staff member asks to rate whether group members participated equally and actively and describe the apparent response from other members of the target audience present. The final report assessment covers demonstration of knowledge and written communication of complex critical analysis. The marking criteria are included in the student handbook for the assessment.

Each group is given detailed written feedback and a breakdown of their overall mark. A whole-cohort feedback session is held after the marks have been released, in which good-practice examples and common pitfalls are discussed. Good practice examples have included the appropriateness of campaign designs (e.g. using social media or video clip-sharing applications to engage with younger audiences), high standards of creativity in the visual appeal of promotional materials and the suitability of approaches for targeting intended audiences (e.g. basing campaigns in venues frequented by target audiences, or getting airtime on popular local radio shows). Specific examples are shown in Table I. Examples of common pitfalls have included producing insufficient quantities of materials, such as leaflets, to last the duration of campaigns and inadequate justification of the methods used to evaluate campaigns. The whole-cohort feedback sessions were also used to evaluate the assessment by students completing an evaluation questionnaire about their learning experience.

\section{Evaluation}

\section{Data collection and analysis}

A questionnaire-based approach to the evaluation was chosen so that a successive series of cohorts could be asked the same questions to allow for comparison. The questionnaire was developed from various sources, including anecdotal feedback from the first cohort of students who undertook the health promotion campaign assignment (2009-2010), staff observations about their performance, the aim and objectives of the study and a review of the literature. Questions developed from students' feedback concerned issues specific to the assessment (e.g. enjoyment of the assignment emerged strongly), as did questions based on staff observations about common issues relating to students' performance 
(e.g. groups' difficulty in choosing campaign topics or locations). Other questions were adapted from routinely used questions to evaluate learning activities on the MPharm. course. The questionnaire was designed as a series of multiple-choice questions using Likert scales and binary 'yes/no' answers to explore students' perceived engagement with the assessment, the learning they had undertaken, equality of group members' contribution, the relevance of the assessment to their likely future practice and their overall enjoyment of the assessment.

Table I: Examples of students' health promotion campaigns

\begin{tabular}{|c|c|c|}
\hline $\begin{array}{l}\text { Assessment } \\
\text { criteria }\end{array}$ & $\begin{array}{l}\text { Example 1: } \\
\text { Hypertension in men }\end{array}$ & $\begin{array}{l}\text { Example 2: } \\
\text { Diabetes in South Asians }\end{array}$ \\
\hline $\begin{array}{l}\text { Rationale } \\
\text { provided for } \\
\text { campaign topic }\end{array}$ & $\begin{array}{l}\text { Evidence of a higher than the national average } \\
\text { prevalence of hypertension among local men. }\end{array}$ & $\begin{array}{l}\text { Evidence of higher than the national average prevalence of } \\
\text { diabetes among local South Asians. Sizeable local } \\
\text { population of South Asians - some older members with } \\
\text { little or no communication in English. }\end{array}$ \\
\hline $\begin{array}{l}\text { Appropriate } \\
\text { campaign venue } \\
\text { chosen }\end{array}$ & $\begin{array}{l}\text { Local football club on match day - as high local } \\
\text { concentration of target audience usually present. }\end{array}$ & $\begin{array}{l}\text { Medical centre, pharmacies and religious venues (e.g. } \\
\text { mosques, temples etc.) in the area with the highest local } \\
\text { population density of South Asians. }\end{array}$ \\
\hline $\begin{array}{l}\text { Effective } \\
\text { campaign design } \\
\text { used }\end{array}$ & $\begin{array}{l}\text { Gazebo near stadium entrance where fans wait, } \\
\text { offering blood pressure testing (with advice if } \\
\text { raised) and lifestyle advice. } \\
\text { Campaign website with advice on what to do if } \\
\text { blood pressure raised, lifestyle advice and contacts } \\
\text { to local and national organisations for further } \\
\text { information and advice. } \\
\text { Feature on the campaign in the match } \\
\text { programme, including photos of players having } \\
\text { their blood pressure tested and a link to the } \\
\text { campaign website. }\end{array}$ & $\begin{array}{l}\text { Leaflets in six common South Asian languages spoken locally } \\
\text { (written and translated by the students) that included } \\
\text { lifestyle advice tailored to South Asians. } \\
\text { Medical centre: event with stands in two locations in the } \\
\text { centre from which students distributed the leaflets and } \\
\text { other promotional material (e.g. healthy versions of South } \\
\text { Asian recipes) and provided verbal lifestyle advice. } \\
\text { Other venues: visits before the event to advertise it (e.g. } \\
\text { with posters and flyers). Visits on the day to distribute } \\
\text { leaflets and advertise the event. }\end{array}$ \\
\hline $\begin{array}{l}\text { Appropriate } \\
\text { campaign } \\
\text { evaluation } \\
\text { method used }\end{array}$ & $\begin{array}{l}\text { Questionnaire feedback from men who attended } \\
\text { the campaign. Verbal feedback from the football } \\
\text { club based on their impression. Comments posted } \\
\text { on the fans' website. }\end{array}$ & $\begin{array}{l}\text { Questionnaire survey of people who had just left the } \\
\text { medical centre to ascertain awareness of and engagement } \\
\text { with the campaign. Verbal feedback from medical centre } \\
\text { staff. }\end{array}$ \\
\hline
\end{tabular}

The first draft of the questionnaire was piloted with the 2010-2011 cohort. It included a free-text box for comments about the questionnaire, such as the coherence and order of questions, the presence of typographical or grammatical errors, and whether any of the questions appeared to be leading or ambiguous. It was administered in a paper-based format at the whole-cohort feedback session, held after the marks and individual feedback had been released. Students voluntarily and anonymously completed it. The paper-based approach was chosen to maximise the response rate, given our experience of lower response rates to previous online questionnaires compared to paper-based ones. Following minor amendments to question wording and order, the questionnaire was similarly administered to the following six cohorts, without being amended when the peer assessment component was added to the assignment in 2015-2016 (i.e. with the fifth cohort of the six who completed the questionnaire evaluation).

Responses were initially entered into a Microsoft Excel spreadsheet for descriptive statistical analysis. Likert scale responses and binary 'yes/no' responses were converted to numerical values, and as ordinal data, median scores were calculated.

For inferential statistical analysis (using SPSS version 24), Likert scale data were converted to binary $1 / 0$ format and to avoid bias in favour of the assignment, neutral scores were added to negative scores (e.g. 'strongly agree' scores and 'agree' scores were assigned a value of 1 , whereas 'strongly disagree' scores, 'disagree' scores and 'neither agree nor disagree' scores were assigned a value of 0 ). To assess the effect of the peer assessment component, Fisher's Exact test was used to compare differences between the responses from the two cohorts who completed the health promotion campaign assessment prior to the introduction of the peer assessment component with the two cohorts who completed the assessment after it was introduced. Logistic regression analysis was conducted to determine whether any of the issues covered by the questionnaire were predictive of the reported overall enjoyment of the health promotion campaign assignment since enjoyment emerged as a strong feature of the assignment in early anecdotal feedback. Odds ratios with corresponding $95 \%$ confidence 
intervals were calculated. The results of these inferential analyses were considered to be significant if $p<0.05$.

When the study commenced, it was considered a module evaluation, and ethical approval was not required. This was confirmed by the Chair of the School's Ethics Committee following a review of the questionnaire. Completion of the questionnaire was not mandatory, and submission of a completed questionnaire was taken as meaning that consent to participate was given. In addition, the final question in the questionnaire asked respondents to confirm their consent for the anonymised data to be used for academic purposes, including publication. All respondents without exception confirmed their consent for this.

\section{Results}

The response rates obtained for the evaluation questionnaire are shown in Table II, which indicates that each year a very high proportion of students who attended the whole-cohort feedback session completed the questionnaire, but only approximately half the cohort attended the session each year.

Table II: Response rates to the evaluation questionnaire

\begin{tabular}{|c|c|c|c|c|c|c|c|}
\hline \multirow[t]{2}{*}{ Variable } & \multicolumn{6}{|c|}{ Cohort No. } & \multirow{2}{*}{ Mean } \\
\hline & 1 & 2 & 3 & 4 & 5 & 6 & \\
\hline Cohort response rate (\%) & 46 & 66 & 61 & 43 & 45 & 47 & 52 \\
\hline Total number of responses & 32 & 51 & 51 & 46 & 38 & 50 & 45 \\
\hline $\begin{array}{l}\text { Female : male respondents } \\
(\%)\end{array}$ & $24: 8(75: 25)$ & $\begin{array}{c}38: 13 \\
(75: 25)\end{array}$ & $\begin{array}{c}27: 24 \\
(53: 47)\end{array}$ & $\begin{array}{l}32: 14 \\
(70: 30)\end{array}$ & $32: 6(84: 16)$ & $\begin{array}{c}36: 14 \\
(72: 28)\end{array}$ & $\begin{array}{c}32: 13 \\
(72: 28)\end{array}$ \\
\hline $\begin{array}{l}\text { Number of students at } \\
\text { session where questionnaire } \\
\text { administered }\end{array}$ & 32 & 52 & 51 & 47 & 38 & 54 & 46 \\
\hline Cohort size & 69 & 77 & 83 & 106 & 85 & 106 & 88 \\
\hline $\begin{array}{l}\text { Response rate from session } \\
\text { attendees (\%) }\end{array}$ & 100 & 98 & 100 & 98 & 100 & 93 & 98 \\
\hline
\end{tabular}

Table III shows questions where the median scores were the same for each cohort, whilst Table IV shows questions where the median scores varied between cohorts. These show that there was a considerable degree of similarity between the responses given by each cohort and consistently that more students reported that the health campaign assessment had been a positive experience than a negative experience.

Table III: Questions where the median score was the same for each of the six cohorts

\begin{tabular}{|c|c|c|c|}
\hline Question & $\begin{array}{l}\text { Median } \\
\text { score }\end{array}$ & Response & Scale \\
\hline The teaching sessions prepared you for carrying out the health campaign & 2 & Agree & $\begin{array}{l}\text { 5-point Likert } \\
\text { (1=strongly agree; } \\
\text { 5=strongly disagree) }\end{array}$ \\
\hline $\begin{array}{l}\text { Did you feel you had enough knowledge and skills to effectively plan your } \\
\text { campaign }\end{array}$ & 1 & Yes & Yes / No \\
\hline Conducting the campaign in a group was a good idea & 1 & Yes & Yes / No \\
\hline All the group members played an equal role in conducting the campaign & 1 & Yes & Yes / No \\
\hline $\begin{array}{l}\text { The health promotion campaign activity was NOT a suitable masters-level } \\
\text { activity }\end{array}$ & 2 & No & Yes / No / Don't know \\
\hline $\begin{array}{l}\text { There should be a peer assessment component for each individual's work in } \\
\text { their team }\end{array}$ & 2 & Agree & $\begin{array}{l}\text { 5-point Likert } \\
\text { (1=strongly agree; } \\
\text { 5=strongly disagree) }\end{array}$ \\
\hline $\begin{array}{l}\text { The campaign felt as though it was a true to life activity that pharmacists } \\
\text { might undertake }\end{array}$ & 1 & Yes & Yes / No \\
\hline This activity has prepared you for health promotion in practice & 2 & Agree & $\begin{array}{l}\text { 5-point Likert } \\
\text { (1=strongly agree; } \\
\text { 5=strongly disagree) }\end{array}$ \\
\hline
\end{tabular}


Table IV: Questions where the median score varied between cohorts

\begin{tabular}{|c|c|c|c|c|c|c|c|}
\hline \multirow[t]{2}{*}{ Question } & \multirow[b]{2}{*}{1} & \multirow[b]{2}{*}{2} & \multicolumn{3}{|c|}{ Cohort No. } & \multirow[b]{2}{*}{6} & \multirow{2}{*}{ Scale } \\
\hline & & & 3 & 4 & 5 & & \\
\hline $\begin{array}{l}\text { All the group members played an equal role in } \\
\text { planning the campaign }\end{array}$ & $1.5^{*}$ & 1 & 1 & 1 & 1 & 1 & \multirow{2}{*}{ Yes $=1 / \mathrm{No}=0$} \\
\hline $\begin{array}{l}\text { All the group members played an equal role in } \\
\text { writing the final report }\end{array}$ & $1.5^{*}$ & 1 & 1 & 1 & 1 & 1 & \\
\hline $\begin{array}{l}\text { Choosing a topic for the health promotion } \\
\text { campaign was easy }\end{array}$ & 2 & 3 & 2 & 2 & 2 & 2 & \multirow{4}{*}{$\begin{array}{l}\text { 5-point Likert } \\
\text { (1= Strongly } \\
\text { agree; } \\
\text { 5=strongly } \\
\text { disagree) }\end{array}$} \\
\hline $\begin{array}{l}\text { Identifying a location in which to hold the health } \\
\text { promotion campaign was easy }\end{array}$ & 3 & 3 & 3 & 3 & 2 & 2 & \\
\hline The support offered by tutors was helpful & 2 & 1 & 2 & 2 & 2 & 2 & \\
\hline Overall, I enjoyed the health promotion campaign & 2 & 1 & 2 & 2 & 2 & 2 & \\
\hline
\end{tabular}

*Half scores indicate that the number of respondents was exactly split in half between two options

The consistently reported desire for a peer assessed component of the assessment resulted in a web-based peer assessment tool that students could anonymously use to score group members being introduced in cohort 5 . Comparison of the two cohorts prior to the introduction of peer assessment (cohorts 3 and 4) with the two cohorts following its introduction (cohorts 5 and 6 ) showed that more respondents in cohorts 5 and 6 reported that peer assessment was useful and that group members had played an equal role in planning the campaign compared to cohorts 3 and 4 . This difference was statistically significant, as shown in Table V. However, Table V also shows that the introduction of the peer assessment component did not have a statistically significant effect on students' rating of the overall enjoyment of the assessment or on the numbers reporting equal contribution from group members in conducting the campaign or writing the final report.

Logistic regression analysis showed that there was a statistically significant association between reported overall enjoyment of the health promotion campaign assessment and three issues, as shown in Table VI. These were whether the activity was reported to have prepared respondents for health promotion in practice, whether respondents reported that identifying a location in which to hold the health promotion campaign had been easy and reporting that there should be a peer assessment component for each individual's work in their group.

Table V: Comparison of responses from the two cohorts before peer assessment was introduced with the two cohorts after it was introduced

\begin{tabular}{|c|c|c|c|}
\hline \multirow[b]{2}{*}{ Independent variable } & \multicolumn{2}{|c|}{ Percentage of answers $=1$} & \multirow[b]{2}{*}{ Significance } \\
\hline & $\begin{array}{c}\text { Before peer } \\
\text { assessment } \\
\text { (cohorts 3\&4) }\end{array}$ & $\begin{array}{c}\text { After peer } \\
\text { assessment } \\
\text { (cohorts 5\&6) }\end{array}$ & \\
\hline Peer assessment of health promotion campaigns would be useful & 55.7 & 83.0 & $<0.01$ \\
\hline All the group members played an equal role in planning the campaign & 61.9 & 77.3 & 0.03 \\
\hline This activity has prepared you for health promotion in practice & 95.3 & 87.5 & 0.06 \\
\hline I understood what was needed in the final report & 77.3 & 87.5 & 0.09 \\
\hline $\begin{array}{l}\text { There should be a peer assessment component for each individual's work in } \\
\text { their team }\end{array}$ & 63.9 & 75.0 & 0.11 \\
\hline The teaching sessions prepared you for carrying out the health campaign & 70.1 & 80.7 & 0.13 \\
\hline Identifying a location in which to hold the health promotion campaign was easy & 86.6 & 93.2 & 0.16 \\
\hline All the group members played an equal role in writing the final report & 62.9 & 72.7 & 0.16 \\
\hline All the group members played an equal role in conducting the campaign & 68.0 & 77.3 & 0.19 \\
\hline Choosing a topic for the health promotion campaign was easy & 54.6 & 63.6 & 0.23 \\
\hline Overall, I enjoyed the health promotion campaign & 86.6 & 80.7 & 0.32 \\
\hline The support offered by tutors was helpful & 96.9 & 95.5 & 0.71 \\
\hline $\begin{array}{l}\text { I felt I had enough knowledge and skills to effectively plan your health } \\
\text { promotion campaign }\end{array}$ & 92.8 & 94.3 & 0.77 \\
\hline Conducting the health promotion campaign in a group was a good idea & 95.9 & 95.5 & 1.00 \\
\hline
\end{tabular}


Table VI: Logistic regression (multivariate) analysis: predictors of overall enjoyment of the health promotion campaign assignment

\begin{tabular}{|c|c|c|c|c|}
\hline \multirow[t]{2}{*}{ Independent variable } & \multirow{2}{*}{$\begin{array}{l}\text { Odds } \\
\text { Ratio }\end{array}$} & \multicolumn{2}{|c|}{ 95\% confidence interval } & \multirow{2}{*}{ Significance } \\
\hline & & Lower & Upper & \\
\hline This activity has prepared you for health promotion in practice & 9.90 & 2.23 & 44.06 & $<0.01$ \\
\hline $\begin{array}{l}\text { Identifying a location in which to hold the health promotion campaign } \\
\text { was easy }\end{array}$ & 7.22 & 1.54 & 33.84 & 0.01 \\
\hline $\begin{array}{l}\text { There should be a peer assessment component for each individual's } \\
\text { work in their group }\end{array}$ & 0.17 & 0.03 & 1.01 & 0.05 \\
\hline $\begin{array}{l}\text { The teaching sessions prepared you for carrying out the health } \\
\text { campaign }\end{array}$ & 2.32 & 0.79 & 6.86 & 0.13 \\
\hline All the team members played an equal role in planning the campaign & 2.79 & 0.55 & 14.24 & 0.22 \\
\hline Peer assessment of health promotion campaigns would be useful & 2.27 & 0.60 & 8.63 & 0.23 \\
\hline $\begin{array}{l}\text { I felt I had enough knowledge and skills to effectively plan your health } \\
\text { promotion campaign }\end{array}$ & 2.07 & 0.36 & 11.91 & 0.42 \\
\hline $\begin{array}{l}\text { Conducting the health promotion campaign in a group was a good } \\
\text { idea }\end{array}$ & 1.61 & 0.26 & 10.16 & 0.61 \\
\hline I understood what was needed in the final report & 1.37 & 0.41 & 4.57 & 0.61 \\
\hline $\begin{array}{l}\text { All the team members played an equal role in conducting the } \\
\text { campaign }\end{array}$ & 1.70 & 0.2 & 14.73 & 0.63 \\
\hline The support offered by tutors was helpful & 0.73 & 0.06 & 9.83 & 0.82 \\
\hline All the team members played an equal role in writing the final report & 1.05 & 0.21 & 5.35 & 0.95 \\
\hline Choosing a topic for the health promotion campaign was easy & 0.98 & 0.34 & 2.88 & 0.97 \\
\hline
\end{tabular}

\section{Discussion and future plans}

The findings of this study indicate that there is a statistically significant positive association between students finding the health promotion campaign assessment to be enjoyable and perceiving that the activity had prepared them for health promotion in practice. The findings also show that consistently more students reported the assessment as a positive experience than a negative experience. Students consistently perceived the assessment to be appropriately challenging at Master's level and adequately supported by staff. In addition, the findings indicate that students' overall enjoyment of the assessment is statistically significantly associated with the view that there should be a peer assessment component. As such, the aim of the evaluation was met, which was to determine whether students perceived that the assessment was an appropriately challenging, adequately supported and enjoyable learning experience in health promotion that prepared them for real practice in public health pharmacy. The aim of the serial cross-sectional element of the study was also met since this allowed for peer assessment to be identified as an important issue that affected students' learning experience and to show that this was improved by introducing a peer assessment component.

In terms of preparing students for health promotion in practice, by designing, delivering and evaluating a reallife health promotion campaign in the local community, students were required to demonstrate a range of skills or competencies. These were public health-related to a certain extent, but also of a generic professional nature. For example, we commonly observed that students anecdotally reported having improved their ability to deliver specifically targeted brief lifestyle advice, which is partly a matter of deciding what to say and to whom, but also a matter of having effective interpersonal skills, resilience and self-confidence. As such, depending on previous experiences, the assessment for some students seemed to be further practice but essentially the demonstration of skills they had already developed, whilst for others undertaking a real-life health promotion campaign appeared to offer the opportunity for skill development. In either case and all points in between, this meant that students met the learning outcome of demonstrating a systematic understanding of the concepts of public health, health inequalities and health promotion, and that they were able to develop an original health promotion campaign by drawing on a systematic and integrated knowledge of applied therapeutics in the context of public health. They also clearly met the health promotion-related competencies to be achieved by the end of their MPharm. degree, as set by the General Pharmaceutical Council (GPhC), the main one of which is now that students need to 'show how' they "effectively promote healthy lifestyles using evidence-based techniques" (UK General Pharmaceutical Council, 2021).

Whilst these findings are entirely consistent with experiential learning theory (Lave, 1993; Kolb, 1994; Tennant \& Pogson, 
1994; Race, 2005; Herrington \& Herrington, 2006), they have nevertheless not been previously reported in any practical health promotion activity in pharmacy education. This is partly because in previous studies, students were not required to design, deliver and evaluate a real health promotion campaign, but also because previous evaluations of public health activities have focused on pharmacy students' self-reported improvements in selfconfidence and/or knowledge. However, in their study of student environmental health officers planning, running and evaluating health promotion campaigns for students, McCarthy and Pritchard found that $85 \%$ of students reported enjoying the exercise, as well as finding that $90 \%$ reported that it had increased their selfconfidence (McCarthy \& Pritchard, 2002). In this respect, the serial cross-sectional findings of this study strongly support previous study findings and robustly, since high reports of the assignment being a positive experience were consistently found across six cohorts.

Limitations of the study include that although the questionnaire response rates from the whole-cohort feedback session attendees were high, this did not translate into similarly high response rates in overall cohorts. In addition, a greater proportion of respondents identified as female than male. It is acknowledged that the results may have differed had a greater proportion of students participated and if a greater proportion of respondents had identified as male.

Nevertheless, the findings of this study suggest that the inclusion of real-life health promotion campaign assessments into pharmacy programmes as preparation for health promotion in practice is likely to provide contextualisation and enrichment of pharmacy students' learning experience. Such inclusion also offers opportunities for mutually beneficial health promotion collaborations between Schools of Pharmacy and a wide variety of community organisations. The implications of this for the initial education and training for pharmacists would appear to be that Schools of Pharmacy should consider adopting such initiatives into routine practice, and that pharmacy education policy and programme accreditation requirements should endorse this view. This sort of experiential learning activity is also likely to transfer well into the public health content of education and training programmes for other healthcare professionals, and so the authors would recommend wide uptake.

Future work could replicate the assessment and evaluation of it at other institutions to determine the generalisability of the findings or attempt to measure changes in students' competence in the provision of health promotion as a result of such real-life assessments if the authenticity of such an experiential learning experience can be preserved (Herrington \& Herrington, 2006). The assessment could also be adapted to fit the commissioning model of service delivery and could include tendering of proposed campaigns prior to delivering them as a way of assessing how comprehensive the planning process had been.

\section{Conclusions}

These findings suggest that pharmacy students are likely to perceive a real-life health promotion campaign assessment as an appropriately challenging and enjoyable means of preparing them for health promotion in practice.

\section{Competing interests}

The authors declare that there is no competing interest regarding the publication of this paper.

\section{References}

Ajzen, I. (1991). The theory of planned behavior. Organizational Behavior and Human Decision Processes, 50, 179-211. https://doi.org/10.1016/0749-5978(91)90020-T

Anderson, A., \& Good, J-V. (2006). Engaging students in wellness and disease prevention services. American Journal of Pharmaceutical Education, 70, Article 40. https://doi.org/10.5688/aj700240

Arbuthnot, E., Hansen-Ketchum, P., Jewers, H., Moseley, J., \& Wilson, C. (2007). Bringing theory to life: Engaging nursing students in a collaborative population-based screening project. International Journal of Nursing Education and Scholarship, 4(3). https://doi.org/10.2202/1548-923X.1358

Becker, M. (1974). The Health Belief Model and personal health behaviour. Health Education Monographs, 2: 324-473

Brown, D., Portlock, J., \& Rutter, P. (2012). Review of services provided by pharmacies that promote healthy living. International Journal of Clinical Pharmacy, 34, 399-409. https://doi.org/10.1007/s11096-012-9634-2

Brown, T., Todd, A., O'Malley, C., Moore, H., Husband, A., Bambra, C., Kasim, A., Sniehotta, F., Steed, L., Smith, S., Nield, L., \& Summerbell, C. (2016). Community pharmacy-delivered interventions for public health priorities: a systematic review of interventions for alcohol reduction, smoking cessation and weight management, including meta-analysis for smoking cessation. BMJ Open, 2016(6), e009828. https://doi.org/10.1136/bmiopen-2015-009828

Carter, J., \& Cochran, G. (2002). Service-learning projects in public health in pharmacy course. American Journal of Pharmacy Education, 66, 312-318 
Eades, C., Ferguson, J., \& O'Carroll, R. (2011). Public health in community pharmacy: A systematic review of pharmacist and consumer views. BMC Public Health, 11, 582. https://doi.org/10.1186/1471-2458-11-582

Gelayee, D., \& Mekonnen, G. (2018). Pharmacy students' provision of health promotion counselling services during a community pharmacy clerkship: a cross sectional study, Northwest Ethiopia. BMC Medical Education, 18, 95. https://doi.org/10.1186/s12909-018-1216-0

Harden, R., \& Stamper, N. (1999). What is a spiral curriculum? Medical Teacher, 21, 141-142. https://doi.org/10.1080/01421599979752

Herrington, A., \& Herrington, J. (2006). Authentic Learning Environments in Higher Education. Idea Group Inc

Kolb, D. (1984). Experiential Learning: Experience as the source of learning and development. Prentice Hall

Lave, J. (1993). The practice of learning. In: Chaiklin, S. \& Lave, $\mathrm{J}$ (Ed.) Understanding practice: Perspectives on activity and context. (pp. 3-32). Cambridge University Press

Linh Banh, H., Chow, S., Li. S., Letassy, N., Cox, C., \& Cave, A. (2015). Pharmacy students screening for prediabetes/diabetes with a validated questionnaire in community pharmacies during their experiential rotation in Alberta, Canada. Sage Open Medicine, 3, 2050312115585040. https://doi.org/10.1177/2050312115585040smo.sagepub.com

McCarthy, A., \& Pritchard, C. (2002). Developing student environmental health officers' skills in health promotion. Journal of Environmental Health Research, 1, 1

Michie, S, van Stralen, M, \& West, R. (2011). The behaviour change wheel: A new method for characterising and designing behaviour change interventions. Implementation Science, 6, 42. https://doi.org/10.1186/1748-5908-6-42

Miller, G. (1990). The assessment of clinical skills/ competence/ performance. Academic Medicine, 65, 563-567. https://doi.org/10.1097/00001888-199009000-00045

Murphy, B., Dipietro, N., \& Kier, K. (2010). Knowledge and use of folic acid among college women: a pilot health promotion program led by pharmacy students and faculty. Pharmacy Practice (Granada), 8, 220-225. https://doi.org/10.4321/s1886$\underline{36552010000400003}$

Ostroff, J., Wolff, M., Andros, C., \& Nemec, E $2^{\text {nd }}$. (2017). Student pharmacists provide tobacco use prevention education to elementary school children: a pilot experience. Currents in Pharmacy Teaching and Learning, 9, 869-873. https://doi.org/10.1016/i.cptl.2017.05.007

Packard, K., Sexton, E., Spangler, M., \& Walters, R. (2010). A novel cardiovascular risk screening and health promotion service learning course. Currents in Pharmacy Teaching and Learning, 2, 228-237. https://doi.org/10.1016/j.cptl.2010.07.001

Prochaska, J.O., \& DiClemente, C.C. (1994). The Transtheoretical Approach: Crossing Traditional Boundaries of Therapy. Dow Jones Irwin

Race, P. (2005). Making learning happen. A guide for postcompulsory education. Sage

Sookaneknum, P., Suttajit, S., Ploylearmsang, C., Kanjanasilp, J., \& Maleewong, U. (2009). Health promotion integrated into a Thai PharmD curriculum to improve pharmacy practice skills. American Journal of Pharmacy Education, 73, Article 78.

Tennant, M., \& Pogson, P. (1984). Learning and change in the adult years: a developmental perspective. Jossey-Bass

UK. Department of Health. (2019). Interim NHS People Plan: the future pharmacy workforce (online). Available at: https://www.longtermplan.nhs.uk/wpcontent/uploads/2019/06/ipp-p-future-workforce.pdf

UK. General Pharmaceutical Council. (2021). Initial education and training for pharmacists (online). Available at: https://www.pharmacyregulation.org/initial-training

UK. Health Education England. (2021). Making Every Contact Count (online). Available at: http://www.makingeverycontactcount.co.uk/

UK. Quality Assurance Agency for Higher Education. (2014). UK Quality code for higher education. Part A: Setting and maintaining academic standards. The frameworks for higher education qualifications of UK degree-awarding bodies (online). Available at: https://www.qaa.ac.uk/docs/qaa/quality-code/qualificationsframeworks.pdf

UK. Quality Assurance Agency for Higher Education. (2015). Characteristics statement. Master's degree (online). Available at: https://www.qaa.ac.uk/docs/qaa/quality-code/master's-degreecharacteristics-statement8019abbe03dc611ba4caff140043ed24.pdf

US. Accreditation Council for Pharmacy Education. (2016). Accreditation standards and guidelines for the professional program in pharmacy leading to the Doctor of Pharmacy degree ("Standards 2016") (online). Available at: https://www.acpeaccredit.org/pdf/Standards2016FINAL.pdf

World Health Organisation. (1998). Health promotion (online). Available at: https://www.who.int/health-topics/health-promotion\#tab=tab 1 